\title{
Type III Effector Diversification via Both Pathoadaptation and Horizontal Transfer in Response to a Coevolutionary Arms Race
}

\author{
Wenbo Ma ${ }^{1}$, Frederick F. T. Dong ${ }^{1}$, John Stavrinides ${ }^{1}$, David S. Guttman ${ }^{1,2^{*}}$ \\ 1 Department of Cell and Systems Biology, University of Toronto, Toronto, Ontario, Canada, 2 Centre for the Analysis of Genome Evolution and Function, University of \\ Toronto, Toronto, Ontario, Canada
}

The concept of the coevolutionary arms race holds a central position in our understanding of pathogen-host interactions. Here we identify the molecular mechanisms and follow the stepwise progression of an arms race in a natural system. We show how the evolution and function of the HopZ family of type III secreted effector proteins carried by the plant pathogen Pseudomonas syringae are influenced by a coevolutionary arms race between pathogen and host. We surveyed 96 isolates of $P$. syringae and identified three homologs (HopZ1, HopZ2, and HopZ3) distributed among $\sim 45 \%$ of the strains. All alleles were sequenced and their expression was confirmed. Evolutionary analyses determined that the diverse HopZ1 homologs are ancestral to $P$. syringae, and have diverged via pathoadaptive mutational changes into three functional and two degenerate forms, while HopZ2 and HopZ3 have been brought into $P$. syringae via horizontal transfer from other ecologically similar bacteria. A PAML selection analysis revealed that the C terminus of HopZ1 is under strong positive selection. Despite the extensive genetic variation observed in this family, all three homologs have cysteine-protease activity, although their substrate specificity may vary. The introduction of the ancestral hopZ1 allele into strains harboring alternate alleles results in a resistance protein-mediated defense response in their respective hosts, which is not observed with the endogenous allele. These data indicate that the $P$. syringae HopZ family has undergone allelic diversification via both pathoadaptive mutational changes and horizontal transfer in response to selection imposed by the host defense system. This genetic diversity permits the pathogen to avoid host defenses while still maintaining a virulence-associated protease, thereby allowing it to thrive on its current host, while simultaneously impacting its host range.

Citation: Ma W, Dong FFT, Stavrinides J, Guttman DS (2006) Type III effector diversification via both pathoadaptation and horizontal transfer in response to a coevolutionary arms race. PLoS Genet 2(12): e209. doi:10.1371/journal.pgen.0020209

\section{Introduction}

The paradigm of the coevolutionary arms race has had a tremendous influence on our interpretation of pathogen-host interactions [1]. It has profoundly influenced our understanding of the mechanisms by which genetic variation is maintained in populations, and how variation in one species influences the evolutionary trajectory of interacting species $[2,3]$. Because of this central role, it is important to dissect the molecular basis and dependencies of this process to fully understand the evolutionary forces and molecular and ecological interactions that drive the stepwise escalatory adaptations that are the hallmark of coevolutionary arms races.

Bacterial virulence proteins secreted through the type III secretion system (T3SS) and the host defense proteins that respond to them are likely instigators and agents of arms races. The T3SS is a specialized injection apparatus used by many Gram-negative bacteria to directly deliver bacterial type III secreted effectors (T3SEs) into the cytosol of their eukaryotic hosts [4]. T3SEs play integral roles in bacterial virulence by promoting pathogen growth [5] and suppressing host defense pathways [6]. Due to their central role in pathogenesis and direct and intimate interactions with substrates inside the host cell, T3SEs impose strong selective pressures on the host [7], while being exposed to reciprocal selective pressures imposed by the host defense systems [8]. Plant hosts have responded to these bacterial challenges by evolving resistance $(\mathrm{R})$ proteins that trigger a defense response upon recognition of specific T3SEs [9]. Pathogens may then respond by modifying or even losing the T3SE so that they are no longer detected [10]. In this manner, bacterial T3SEs and plant $\mathrm{R}$ proteins are engaged in a classic coevolutionary arms race $[2,3,11]$.

One of the most diverse and widely distributed families of T3SEs is the Yersinia pestis YopJ family of cysteine proteases [12]. Members of this large family of T3SEs are found among both animal and plant pathogens, implying that they may target conserved eukaryotic substrates. YopJ homologs have been shown to suppress immune responses in both animal and plant hosts, either by mimicking the enzymatic activity of

Editor: Harmit Singh Malik, Fred Hutchinson Cancer Research Center, United States of America

Received August 10, 2006; Accepted October 25, 2006; Published December 22, 2006

A previous version of this article appeared as an Early Online Release on October 25, 2006 (doi:10.1371/journal.pgen.0020209.eor).

Copyright: (C) $2006 \mathrm{Ma}$ et al. This is an open-access article distributed under the terms of the Creative Commons Attribution License, which permits unrestricted use, distribution, and reproduction in any medium, provided the original author and source are credited.

Abbreviations: bp, base pair; HR, hypersensitive response; MLST, multilocus sequence typing; T3SE, type III secreted effector; T3SS, type III secretion system

* To whom correspondence should be addressed. E-mail: david.guttman@ utoronto.ca 


\section{Synopsis}

Pathogens and their hosts impose reciprocal selective pressures on each other, such that the improvement of one selects for the improvement of the other. Pathogens that are able to evolve increasingly effective methods of attacking their hosts select for hosts that are able to mount increasingly effective defenses against pathogen attack. This coevolutionary interaction is commonly referred to as an arms race, or the Red Queen Principle, taken from Lewis Carroll's Through the Looking Glass, and What Alice Found There, in which Alice and the Red Queen had to run as fast as they could simply to stay in the same place. Many pathogenic bacteria rely on specialized virulence proteins, called type III secreted effectors (T3SEs), to cause disease. These proteins are injected into the cells of the host, and often act to disrupt the host defense response. This study shows how the HopZ family of T3SEs in the pathogen Pseudomonas syringae evolves in response to coevolutionary selective pressures imposed by its plant hosts. The authors identify the version of the hopZ gene that is most similar to the one carried by the ancestral strain, and then show how this version has been modified by mutation and selection in response to the host defense systems. They also identify genes related to hopZ from other species that were brought into $P$. syringae presumably in response to this same host-imposed selective pressure. Finally, the authors show how the genetic diversity in this gene family permits the pathogen to avoid host defenses while still maintaining an important virulence-associated function. This study provides a clearer picture of the molecular interactions that drive coevolutionary interactions, and insight into how ecological processes play out at the molecular and evolutionary scale.

the small ubiquitin-related modifier protease inside eukaryotic cells, or by inhibiting MAPK and NFKB defense signaling pathways [13-15].

In this study we show how YopJ homologs in Pseudomonas syringae, which are referred to as the HopZ family in this species, mediate a classic arms race with their plant hosts. $P$. syringae is an agronomically important plant pathogenic $\gamma$ proteobacterium that causes disease in a wide variety of important crop species. While the host range of the $P$. syringae species is vast, individual isolates typically cause disease in a very restricted set of hosts.

Three YopJ homologs have been identified in P. syringae [16]: HopZ1 (formerly HopPsyH and HopPmaD), HopZ2 (formerly AvrPpiG), and HopZ3 (formerly HopPsyV). HopZ1 was originally identified in the ornamental pear pathogen, $P$. syringae pv. syringae A2 (PsyA2) [17] and the radish pathogen, $P$. syringae pv. maculicola ES4326 (PmaES4326) [18]. HopZ2 was originally identified in the pea pathogen, P. syringae pv. pisi 895A (Ppi895A). All known hopZ2 alleles are located on plasmids and flanked by mobile elements [19]. HopZ3 was originally isolated from the bean pathogen, $P$. syringae pv. syringae B728a (PsyB728a) [20,21]. This T3SE is found in the highly variable exchange effector locus, which lies to one side of the hrp/hrc cluster that encodes the T3SS in P. syringae. HopZ3 was recently shown to suppress the defense signalingassociated cell death in Nicotiana benthamiana, yet it intriguingly acts as an avirulence factor both in this host and in snap bean [22]. Additionally, it facilitates bacterial growth, and thereby acts as a virulence factor in Arabidopsis thaliana [22]. All three of these T3SEs share the cysteine-protease catalytic core consisting of the histidine, glutamic acid, and cysteine residues required for proteolytic function [12].
Previous studies have demonstrated that the inactivation of T3SEs from $P$. syringae and other plant pathogens in agricultural or contrived conditions can profoundly influence pathogen-host interactions [11,23-26]. Most of this work has implicated horizontal gene transfer and the resulting acquisition and loss of T3SE as an important arms race strategy $[27,28]$. The alternative to modulating virulence via horizontal gene transfer is pathoadaptation, in which increased virulence is achieved through relatively minor mutations (e.g., point mutations) in preexisting genes [29-32]. While the evolutionary signature of positive selection has been identified in T3SEs [33], the diversification of T3SEs via pathoadaptive mutational changes has not yet been shown to influence pathogen-host interactions, except in fairly specialized cases when the variation has been introduced by strand-slippage repeat expansion [34,35] or the insertion of mobile elements [36-38]. The $P$. syringae T3SE aurPphE presents a strong case for the importance of mutation in T3SE-mediated pathogen-host interactions, although the support for pathoadaptation in this system is equivocal since the genes were overexpressed using strong constitutive promoters [39].

Here we show through the sampling and analysis of extant alleles from natural populations of $P$. syringae that the HopZ family of T3SEs was present in an early ancestor of the species, and that coevolutionary interactions with the host defense system have resulted in allelic diversification via both pathoadaptive mutation and horizontal gene transfer from ecologically similar bacteria. We demonstrate that this has ultimately resulted in a highly polymorphic T3SE family, with clear implications for $P$. syringae host specificity.

\section{Results/Discussion}

Evolutionary Relationships of $P$. syringae HopZ Homologs

A phylogenetic analysis of the complete YopJ family places the $P$. syringae effectors in three distinct clades (Figure 1A). The HopZ1 alleles form a distinct clade restricted to $P$. syringae. HopZ2 clusters with T3SEs from the tomato and pepper pathogen, Xanthomonas campestris (AvrBsT, AvrRxv, and AvrXv4). HopZ3 is in a distinct clade with the virulenceassociated ORFB locus from the Asian pear pathogen, Erwinia pyrifoliae, and the fire blight pathogen, Erwinia amylovora. These phylogenetic relationships suggest that hopZ1 is native to $P$. syringae, while the clustering of hopZ2 and hopZ3 within clades dominated by Xanthomonas and Erwinia T3SEs, respectively, supports the argument that these T3SEs may be functionally related homologs that were horizontally acquired from ecologically related plant pathogens.

The distribution of the HopZ T3SEs was examined in our collection of $P$. syringae strains isolated worldwide from $\sim 40$ plant hosts. All 96 strains were phylogenetically characterized via multilocus sequence typing (MLST) [40] of the core genome to determine their clonal evolutionary relationships. Both Southern hybridization using T3SE probes and PCR were used to determine the distribution of the HopZ family members. Forty-two isolates, distributed throughout all five $P$. syringae phylogroups [40], were positive for at least one effector (Figure 2). Promoter analysis, RT-PCR, and northern blot analysis (Figure S1) confirmed that a total of 39 isolates from 18 different hosts express hopZ, with 16 strains expressing hopZ1, 13 expressing hopZ2, and ten expressing 

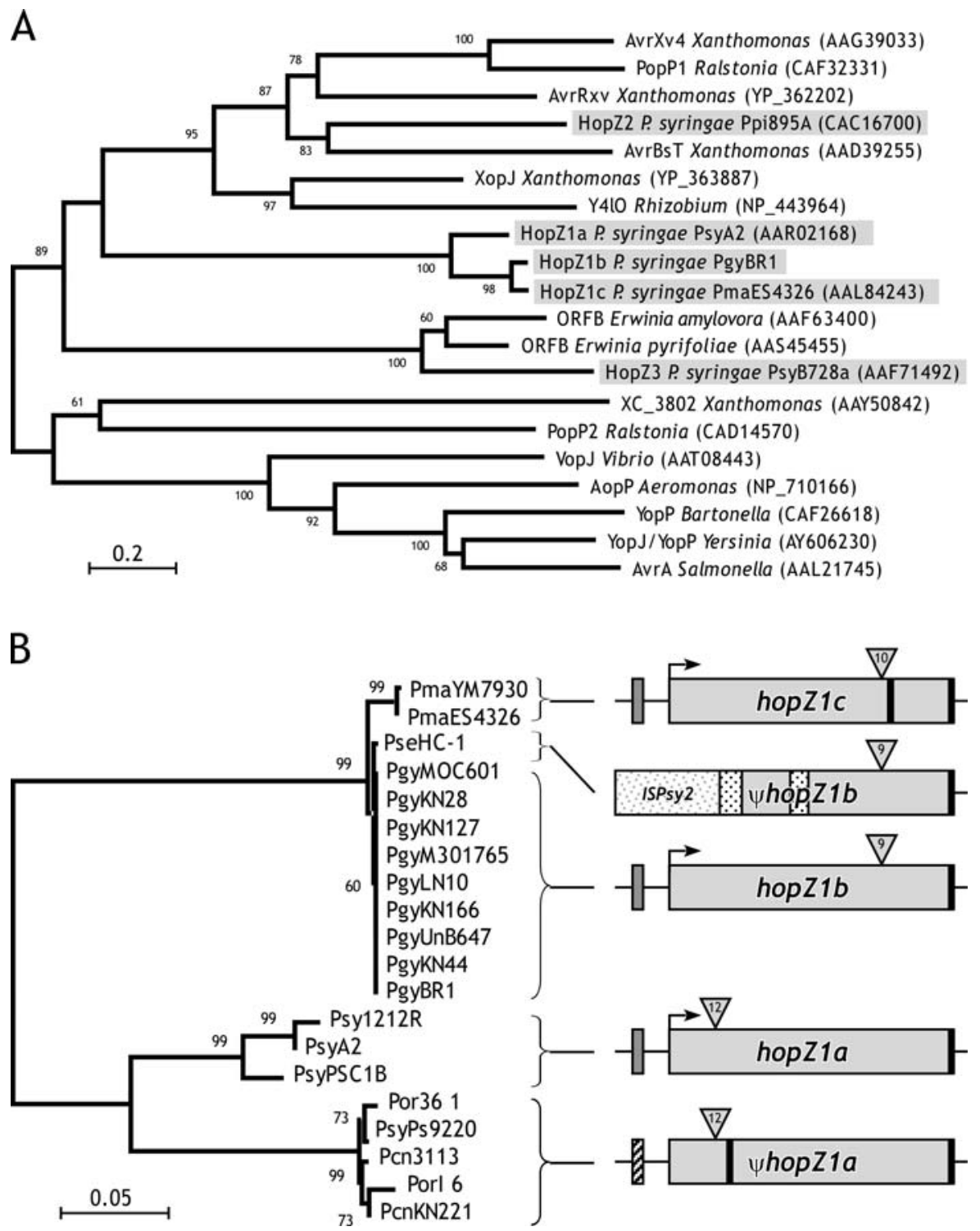

Figure 1. Phylogenetic Analyses

(A) Neighbor-joining tree of YopJ family of T3SEs proteins. Bootstrap support is indicated above each node, with only values $>60 \%$ being shown. T3SEs from $P$. syringae are highlighted. Accession numbers for each protein are presented in parentheses following the protein name and species.

(B) Neighbor-joining gene genealogy of the hopZ1 T3SEs alleles with bootstrap analysis as above and hopZ2Ppi895A used as an out-group. The genetic organization of the three functional allele classes (hopZ1a, hopZ1b, and hopZ1c) and two degenerate hopZ1 alleles ( $\psi$ hopZ1a and $\psi$ hopZ1b) are presented to the right of the gene genealogy. The large gray rectangle represents the region of shared similarity among the alleles, and corresponds to the coding sequence of hopZ1a. The dark vertical rectangle to the left of each gene represents the T3SS promoter element known as the $h r p$ box. The solid black vertical line represents the stop codon for each allele. Arrows at the $5^{\prime}$ end of the coding sequences indicate which alleles are functional. Triangles above each coding sequence indicate insertions, with the insertion size indicated within. The $\psi$ hopZ1a allele has a nonsense mutation at nucleotide 171, and a degenerate hrp box in which the conserved GGAACC sequence has mutated to CCAACC. It is not transcribed under T3SS induction conditions. The $\psi$ hopZ1b allele is disrupted by an insertion sequence.

doi:10.1371/journal.pgen.0020209.g001

hopZ3. No isolates expressed more than one HopZ T3SE, although three strains expressing hopZ2 also carry degenerate forms of hopZ1. The frequency and broad distribution of the HopZ T3SEs suggest that these genes were present in an early ancestor of $P$. syringae.

\section{HopZ1a Is the Ancestral Allelic Form}

A relative-rates test of all hopZ homologs (Figure S2) reveals that the three major forms are evolving in approximately a clock-like manner (unpublished data); however, hopZ1 has significantly higher overall average pairwise nucleotide diversity $(\pi)$ at $0.149 \pm 0.034(\mathrm{sd})$, versus $0.032 \pm 0.006$ and $0.096 \pm 0.035$ for hopZ2 and hopZ3, respectively $(p<0.0001$ for all unpaired $t$-test comparisons), as well as the highest synonymous pairwise nucleotide diversity $(0.234,0.087$, and 0.193 , for $h o p Z 1, h o p Z 2$, and hopZ3, respectively). The clocklike evolution of hopZ1 suggests that its higher genetic diversity is due to a greater age in the population relative to hopZ2 and hopZ3, rather than an accelerated pace of evolution. This supports the hypothesis that hopZ1 is more ancestral than hopZ2 and hopZ3, and that these latter two 


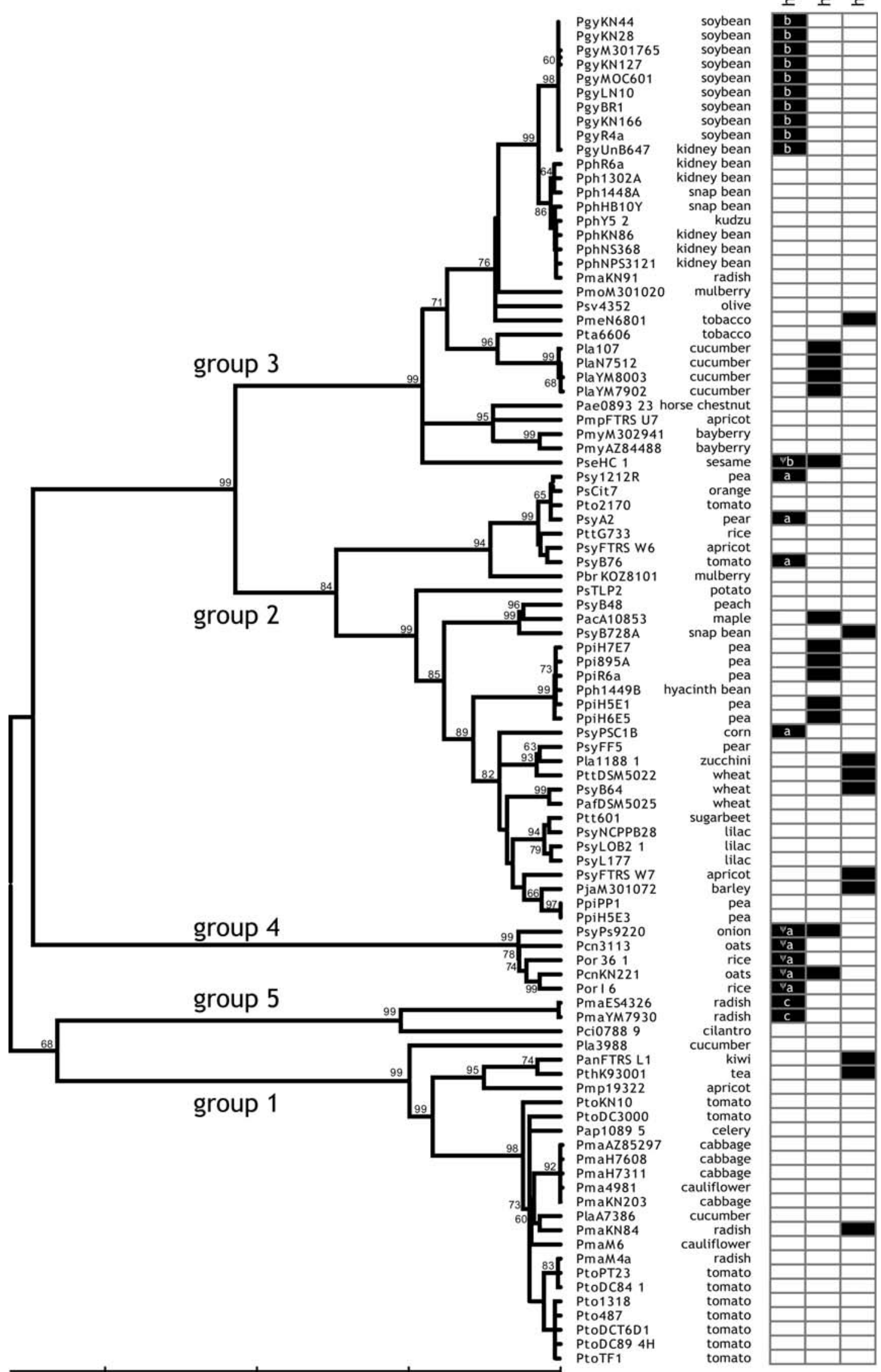


Figure 2. Distribution of HopZ T3SEs in the P. syringae Species Complex

The distribution of HopZ T3SEs in relation to the core genome phylogeny of 96 natural $P$. syringae isolates. The phylogenetic tree (neighbor-joining, 1,000 bootstrap) was generated by MLST of four housekeeping genes. The host of isolation is presented to the right of each strain. See [40,65] and Table $\mathrm{S} 1$ for details. Black squares represent presence of the corresponding gene, whereas white ones represent absence. hopZ1 alleles are annotated. The full sequence of hopZ1 $a_{P_{S y B}}$ was not obtained although its expression was confirmed.

doi:10.1371/journal.pgen.0020209.g002

homologs were brought into $P$. syringae via horizontal transfer after the species began to diversify.

HopZ1 has three functional and two degenerate allelic forms (Figure 1B). Of the functional alleles, hopZ1b and hopZ1c differ from hopZ1a in that they have a 12-base-pair (bp) deletion encompassing amino acids 31-34, which removes a predicted alpha helix [41]. hopZ1b also has a 9-bp insertion near its $3^{\prime}$ end, while hopZ1c has a 10-bp insertion at the same site. The insertion in hopZ1c causes a frameshift that prematurely terminates translation (Figure S3). Although HopZ1c is approximately $25 \%$ shorter than HopZ1a, it still retains the protease catalytic triad and its enzymatic activity (see below). The two degenerate hopZ1 alleles were found in six isolates. One of these alleles is due to a nonsense mutation at nucleotide 171, while the other is due the integration of an insertion sequence. The alleles are not expressed under either T3SS-inducing or rich media.

The clustering of alleles in the hopZ1 gene genealogy is consistent with the major clades (phylogroups) seen in the $P$. syringae MLST core-genome tree (Figure 3). The single largescale incongruence between the hopZ1 gene tree and the core genome phylogeny is the tight clustering between the hopZ1b alleles from phylogroup 3 strains and the hopZ1c alleles from phylogroup 5 strains. Specifically, it appears as if hopZ1 alleles from phylogroup 5 strains transferred into strains of phylogroup 3. An identical incongruity between the phylogroup 3 and 5 strains was observed for one of the major operons that encodes the T3SS apparatus [42]. These results support a horizontal gene exchange event between phylogroups 3 and 5 that mobilized at least part of the genes encoding the T3SS and some of its effectors. There are also some minor points of incongruence within the major clades of the hopZ1 gene genealogy with respect to the MLST coregenome tree, but none of these are strongly supported by bootstrap analysis in both trees. An $\mathrm{SH}$ phylogenetic congruence test [43] for the phylogroup 2, 4, and 5 strains (phylogroup 3 strains were omitted in this analysis for the reason discussed above) also finds that the MLST data is congruent with the HopZ1 tree (unpublished data).

The congruence between the MLST core-genome tree and the HopZ1 tree implies that the genes used in these analyses have a shared evolutionary history. As discussed above, hopZ1 is restricted to $P$. syringae and has significantly greater diversity than hopZ2 or hopZ3. Furthermore, hopZ1a falls in the center of a network phylogenetic analysis (Figure S4). These lines of evidence indicate that a hopZ1a-like allele was present in an early ancestor of $P$. syringae and that the other hopZ1 alleles are mutational derivatives of hopZ1a.

\section{HopZ1 Alleles Are under Strong Positive Selection}

If hopZ1a was carried by an early ancestor of $P$. syringae, it has been lost in many lineages, replaced by mutational derivatives in others, or even substituted for by homologs through horizontal transfer. This is most likely due to selection on HopZ1 for alternative alleles imposed by an arms race. We use the codeml module of PAML [44] to test for selection. PAML is a likelihood-based application for estimating synonymous and nonsynonymous substitution rates and testing various models of evolution in DNA and protein sequences. Codeml can be used to determine the likelihood of positive selection acting on individual codons in a coding sequence. Our analysis finds a very strong and significant footprint of positive selection acting on the functional HopZ1 alleles (Table 1), with $7.2 \%$ of codons having an equilibrium $\mathrm{dN} / \mathrm{dS}=6.69($ model $\mathrm{M} 3)$. These patterns are particularly pronounced in the C- terminus of the protein following the hopZ1c frameshift insertion (Figure 4). Of the 22 positively selected residues, 17 fall after the frameshift

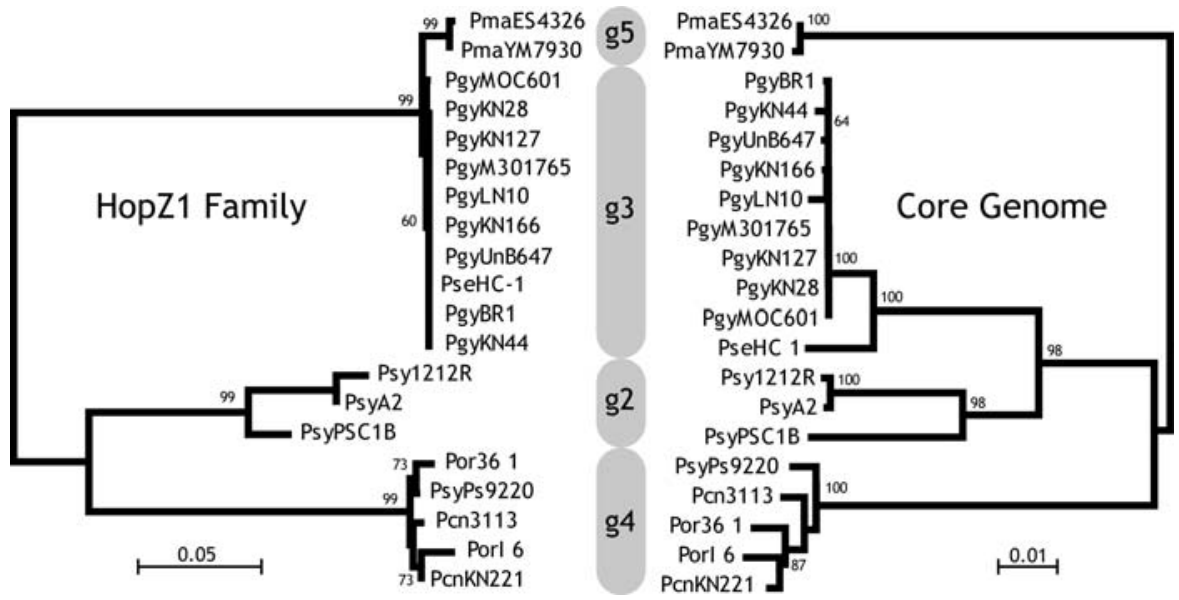

Figure 3. Congruence between the HopZ1 Gene Genealogy and the MLST Core Genome Phylogeny of $P$. syringae

See Figures 2 and $S 1$ for details on the phylogenetic methods used. Gray areas labeled g2-g5 in the center of the figure indicate the major phylogroups as determined by MLST. Bootstrap support values $(>60 \%)$ are indicated above nodes. doi:10.1371/journal.pgen.0020209.g003 
Table 1. PAML Selection Analysis

\begin{tabular}{|c|c|c|c|c|c|}
\hline \multirow[t]{2}{*}{ Model } & \multirow[t]{2}{*}{ Likelihood } & \multirow[t]{2}{*}{ ts/tv } & \multirow[t]{2}{*}{ Average dN/dS } & \multicolumn{2}{|c|}{ Parameter Estimates } \\
\hline & & & & Frequency & dN/dS \\
\hline M0, one-ratio & -2800.35 & 1.88 & 0.299 & $p=1.000$ & $\omega=0.299$ \\
\hline \multirow[t]{2}{*}{ M1, neutral } & -2768.96 & 1.92 & 0.340 & $\mathrm{p}_{0}=0.718$ & $\omega_{0}=0.080$ \\
\hline & & & & $\mathrm{p}_{1}=0.282$ & $\omega_{1}=1.000$ \\
\hline \multirow[t]{3}{*}{ M2, selection } & -2761.25 & 2.01 & 0.575 & $\mathrm{p}_{0}=0.809$ & $\omega_{0}=0.132$ \\
\hline & & & & $\mathrm{p}_{1}=0.130$ & $\omega_{1}=1.000$ \\
\hline & & & & $\mathrm{p}_{2}=0.061$ & $\omega_{2}=7.266$ \\
\hline \multirow[t]{3}{*}{ M3, discrete } & -2760.77 & 2.00 & 0.681 & $\mathrm{p}_{0}=0.360$ & $\omega_{0}=0.000$ \\
\hline & & & & $\mathrm{p}_{1}=0.569$ & $\omega_{1}=0.355$ \\
\hline & & & & $\mathrm{p}_{2}=0.072$ & $\omega_{2}=6.690$ \\
\hline \multirow[t]{2}{*}{ M7, beta } & -2770.70 & 1.96 & 0.354 & $p=0.140$ & \\
\hline & & & & $q=0.256$ & \\
\hline \multirow[t]{4}{*}{ M8, beta and $\omega$} & -2760.89 & 2.00 & 0.681 & $\mathrm{p}_{0}=0.931$ & $\omega=6.840$ \\
\hline & & & & $p=0.640$ & \\
\hline & & & & $\mathrm{p}_{1}=0.069$ & \\
\hline & & & & $q=2.16$ & \\
\hline Likelihood Ratio Test & $\mathbf{2 \Delta l}$ & Df & $\mathbf{p}$ & & \\
\hline M2-M1 & 15.4292 & 2 & $4.46 \times 10^{-4}$ & & \\
\hline M3-M0 & 79.1459 & 4 & $2.22 \times 10^{-16}$ & & \\
\hline M8-M7 & 19.6227 & 2 & $5.48 \times 10^{-5}$ & & \\
\hline
\end{tabular}

ts/tv, transition/transversion ratio.

doi:10.1371/journal.pgen.0020209.t001

mutation, and eight of these follow the premature stop in hopZ1c. An analysis using only the hopZ1a and hopZ1b alleles found many of the same amino acids to be under selection, indicating that while the 19 amino acids in HopZ1c that follow the frameshift strongly contribute to the signature of selection, they are by no means solely responsible for it. Of the five codons in the $\mathrm{N}$-terminal and central portion of the protein identified as being under positive selection, four of these are located very close (between three and nine amino acids) to one of the amino acids in the cysteine-protease catalytic triad, suggesting that these amino acids may be involved in protein-substrate interaction.

\section{HopZ Alleles Are Cysteine Proteases}

While it has been shown that the Yersinia YopJ T3SEs are cysteine proteases [12] or acetyltransferases [15], this has not yet been shown for their $P$. syringae HopZ homologs. Furthermore, the intense selective pressure experienced by HopZ1, which has resulted in a dramatic increase in the rate of nonsynonymous substitutions at the C terminus of HopZ1a and HopZ1b, and perhaps in a frameshift in HopZ1c, raises the possibility that the HopZ alleles may have functionally diverged. To test this, we purified recombinant $P$. syringae HopZ T3SEs and assayed their activity using a fluorescencebased protease assay (Figure 5). The enzymatic activities of

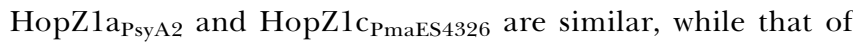
HopZ2 $_{\mathrm{Ppi} 895 \mathrm{~A}}$ is approximately 2-fold higher. The addition of $N$. benthamiana leaf tissue extract to the assays increased the activity of all three enzymes, suggesting that plant cofactors may be required for full cysteine-protease activity. In contrast to HopZ1 and HopZ2, the protease activity of HopZ3 $3_{\text {PsyB728a }}$ could not be consistently measured with this assay; therefore, a gelatine in-gel protease assay was used to confirm its activity. The wild-type HopZ3 $3_{\text {PsyB } 728 a}$ showed strong band clearing, indicating protease activity, although no increase in activity was detected when plant extract was added (unpublished data). No protease activity was detected via the gelatine assay for HopZ1 $\mathrm{a}_{\mathrm{PsyA} 2}$, HopZ1 $\mathrm{C}_{\mathrm{PmaES} 4326}$, and HopZ2 $2_{\mathrm{Ppi} 895 \mathrm{~A}}$. We confirmed the role of the conserved cysteine residue that makes up part of the cysteine protease catalytic triad by testing the activity of mutated HopZ family T3SEs in which the conserved cysteine was changed to alanine. Mutation of the conserved cysteine residue completely abolished protease activity in all assays (Figure 5). These results confirm that all of the HopZ family members are cysteine proteases, although the substrate specificity of HopZ3 may differ.

\section{HopZ Alleles Elicit Defense Responses in a Host-Specific Manner}

How does the genetic variation observed among the HopZ alleles affect the ability of strains to attack their respective host plants? To determine how the ancestral hopZ1a allele influences the interactions between strains carrying derived HopZ alleles and their respective hosts, we transformed $P$. syringae isolates PgyBR1 and PmaES4326, which endogenously carry hopZ1b and hopZ1c, respectively, with the full-length $h o p Z 1 a_{\text {PsyA2 }}$ under the control of its native promoter. These transgenic strains were then infiltrated into their respective plant hosts (soybean and A. thaliana), and the responses of the plants were monitored. Both transformed bacteria elicited a hypersensitive response (HR) - a visible and characteristic component of the plant defense response (Figure $6 \mathrm{~B}$ and $6 \mathrm{C}$ ).

To test if the ancestral hopZ1a allele is detrimental in the strains carrying degenerate hopZ1 alleles, we transformed PseHC-1 (a sesame pathogen carrying $\psi$ hopZ1b) and Por36-1 (a rice pathogen carrying $\psi h o p Z 1 a)$ with hopZ1a $a_{P S y A 2}$ and infiltrated them into their respective hosts. Whereas the wild- 

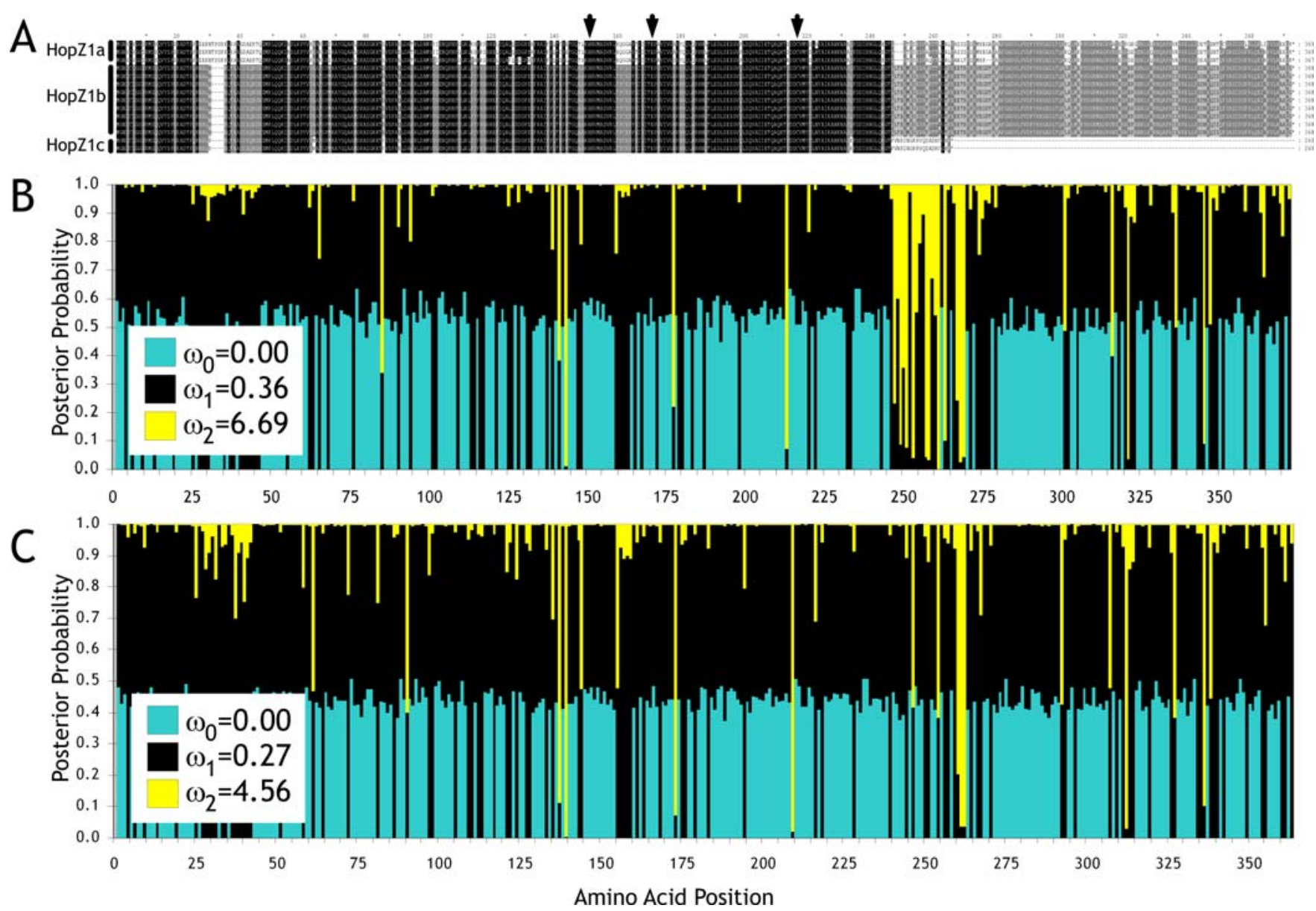

Figure 4. PAML Selection Analysis

(A) Amino-acid alignment of the HopZ1 alleles. See Figure S3 for details. The three amino acids in the catalytic triad are indicated by arrows presented above the alignment.

(B) Stacked histogram representing the posterior probabilities for the three site classes identified by codeml model M3 (discrete) along the HopZ1 sequence for all functional alleles. The $\mathrm{dN} / \mathrm{dS}(\omega)$ values for each site class are given below the figure.

(C) Same as above but using only hopZ1a and hopZ1b to remove the signal from the frameshift mutation in hopZ1c.

doi:10.1371/journal.pgen.0020209.g004

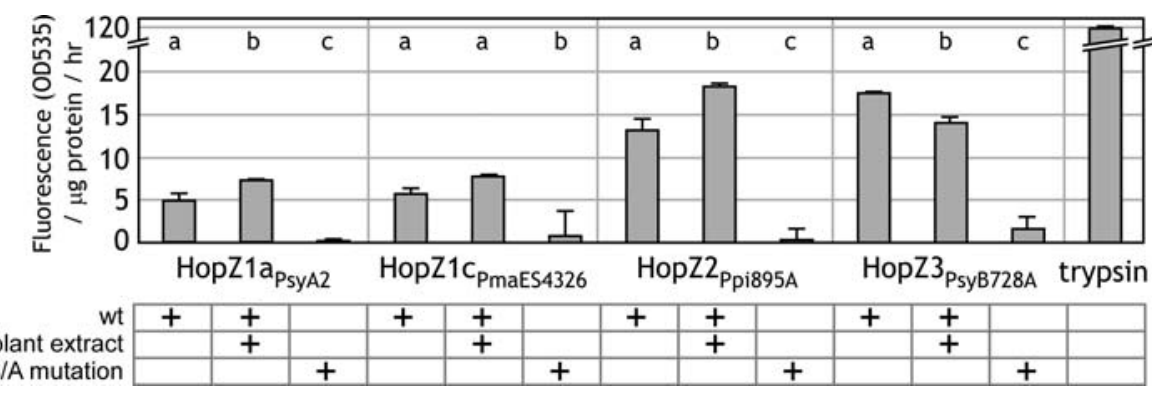

Figure 5. Protease Activity of HopZ T3SEs in P. syringae

Protease activity of HopZ1 $\mathrm{a}_{\mathrm{PsyA} 2}$, HopZ1 $\mathrm{C}_{\mathrm{PmaES} 4326}, \mathrm{HopZ2}_{\mathrm{Pp} \text { 8895A, }}$ and HopZ3 $3_{\mathrm{PsyB} 728 \mathrm{a}}$ measured using Invitrogen RediPlate 96 EnzChek Protease Assay Kit green fluorescence is shown as fluorescence production (OD 535) after a 1-h incubation of the purified His-tag fusion proteins with a green fluorescence-labeled substrate at room temperature. Trypsin was used as a positive control. The grid along the bottom of the figure indicates if the wild-type protein was used, if plant extract was added to the reaction, or if the cysteine-to-alanine mutant protein was used. The error bars indicate

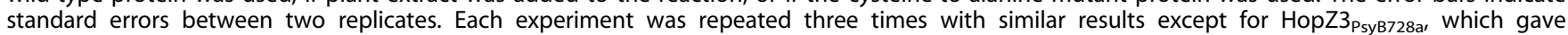
inconsistent results due to instability of the protein. A gelatine in-gel protease assay was performed to confirm the enzymatic activity of HopZ3 PsyB728a. Letters above the histogram bars indicate significance classes from a Fisher's Least Significant Difference test.

wt, wild-type.

doi:10.1371/journal.pgen.0020209.g005 


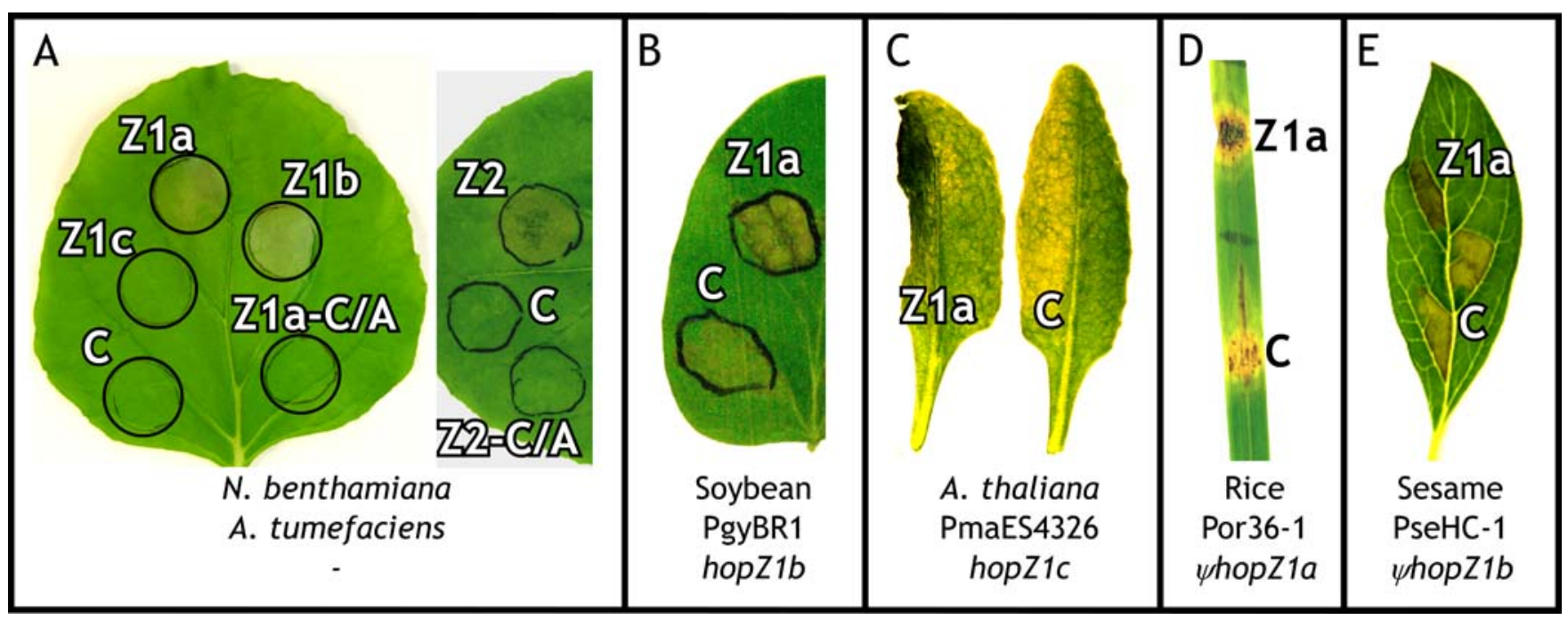

Figure 6. In Vivo Defense Induction Assays

The plant host, infiltrated strain, and hopZ allele carried by the infiltrated strain are indicated below each leaf image.

(A-E) Z1a, Z1b, Z1c, and Z2 represent the infiltration zones of HopZ1a, HopZ1b, HopZ1c, and HopZ2, respectively. Z1a-C/A and Z2-C/A identify the infiltration zone of the HopZ1a and HopZ2 alleles carrying the cysteine-to-alanine replacement in the catalytic core, respectively. $C$ represents the vector control. In all panels HopZ1a induces an HR, while the other infiltrations either result in disease symptoms or no response.

(A) Transient expression assay using $N$. benthamiana leaves infiltrated with A. tumefaciens C58C1(pCH32), carrying HopZ1 or HopZ2 T3SEs in pMDD1 vector.

(B) Soybean (Glycine max cv. OAC Bayfield) leaves infiltrated with PgyBR1, carrying pUCP20 or pUCP20HopZ1a PsyA2. PgyBR1 carries hopZ1b natively.

(C) A. thaliana (column 1) leaves infiltrated with PmaES4326, carrying pUCP20 or pUCP20HopZ1a PsyA2. PmaES4326 carries hopZ1c natively.

(D) Rice (O. sativa cv. Jefferson) leaves infiltrated with Por36-1 carrying pUCP20 or pUCP20HopZ1a PsyA2. Por36-1 carries $\psi$ hopZ1a natively.

(E) Sesame (S. indicum) leaves infiltrated with PseHC-1 carrying pUCP20 or pUCP20HopZ1a PsyAz. PseHC-1 carries $\psi$ hopZ1b natively.

doi:10.1371/journal.pgen.0020209.g006

type strains cause disease symptoms in their hosts, both transformed strains induce an HR (Figure 6D and 6E). These data indicate that an $\mathrm{R}$ protein-mediated defense response is induced by the ancestral HopZ1a, but not for all of the derived homologs, even though all of the T3SEs retain cysteine-protease activity. The ability of plant hosts to recognize and respond to the different HopZ alleles is strongly host-dependent.

We used Agrobacterium-mediated transient expression to further examine the interaction between bacterial and host proteins. This technique permits the expression of individual genes directly inside the host cell, thereby eliminating other variables introduced by the pathogen-host interaction. Transient expression of HopZ1a, HopZ1b, and HopZ2 induced an HR in $N$. benthamiana, while HopZ1c did not (Figure 6A). HopZ3 also did not induce an HR in $N$. benthamiana when expressed either with or without its chaperone (unpublished data), which is consistent with the findings of Deng et al. [20]. These data indicate that specific HopZ alleles induce differential responses in a host-dependent manner, and may therefore contribute to host specificity.

The positively selected genetic variation observed at the Cterminus of HopZ1 may be important either for avoiding recognition by host-resistance proteins or for virulencetarget specificity. While it is possible that the as-yetunidentified $\mathrm{R}$ protein directly recognizes the $\mathrm{C}$-terminus of the HopZ1a protein, Agrobacterium-mediated transient assays expressing a mutated hopZ1a allele with a cysteine-to-alanine replacement in the catalytic triad did not induce an HR in $N$. benthamiana (Figure 6A). The same results were obtained with HopZ2 and the HopZ2 cysteine-to-alanine catalytic mutation (Figure 6A). This confirms that the cysteine-protease func- tion is required for the $\mathrm{R}$ protein-mediated defense induction. These data are consistent with the guard hypothesis of R-protein action [45], which predicts that it is the virulence function of the bacterial effector that induces the defense response. Since it is the proteolytic function that is recognized by the $\mathrm{R}$ protein, the high C-terminal diversity may instead be important for virulence-target specificity.

\section{Evolutionary Implications}

A coevolutionary arms race requires that there be reciprocal selective pressures imposed on two or more species, leading to escalatory adaptations. Escalatory adaptations are those in which evolutionary changes in the pathogen are matched by evolutionary changes in the host, such that the relative balance between these organisms is maintained. In general, these criteria are difficult to meet since they require information about past adaptations and interactions. By combining evolutionary and functional approaches, we have been able to identify a coevolutionary arms race and describe a mechanism for its action (Figure 7). Phylogenetic and population genetic analyses indicate that hopZ1a most closely resembles the ancestral $P$. syringae hopZ cysteine protease. The ancient bacterium that expressed this T3SE must have attacked a host that lacked a cognate $\mathrm{R}$ protein for HopZ1a. Over time, either this ancestral host evolved or acquired the appropriate $\mathrm{R}$ protein, or the ancestral pathogen began infecting host species that already had the appropriate $\mathrm{R}$ protein. This $\mathrm{R}$ protein imposed strong selective pressures on HopZ1a, which resulted in either gene loss, extensive mutational change (pathoadaptation), or the recruitment of homologs from other ecologically similar species by horizontal gene transfer. These new T3SEs retain 


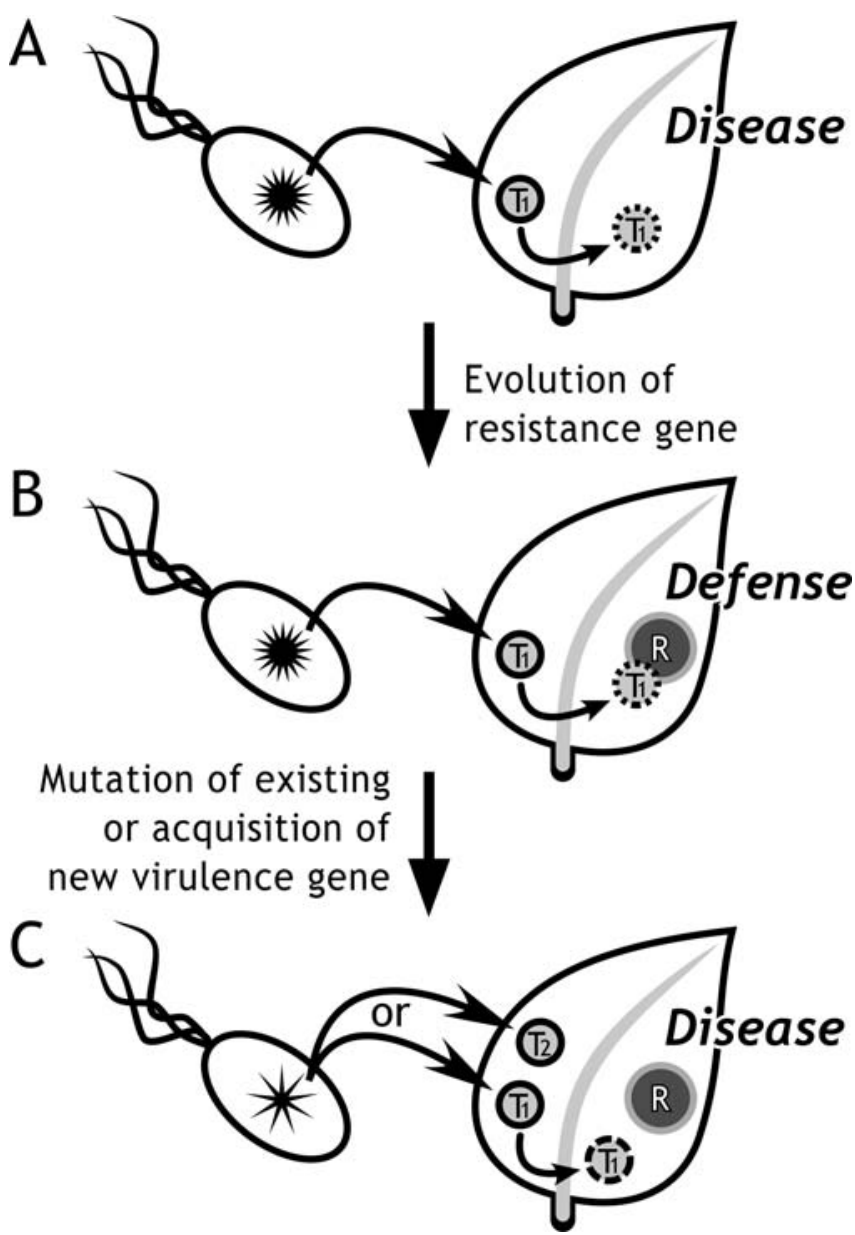

Figure 7. Arms-Race Model

(A-C) Star-shaped figures in bacteria represent T3SEs. $T_{1}$ and $T_{2}$ are two virulence targets in the host. $R$ is a resistance protein that induces the host-defense response upon recognition of a plant-virulence target modified by a bacterial effector.

(A) The pathogen secretes the ancestral HopZ1a T3SE which modifies a host-virulence target and contributes to the disease process.

(B) The plant host evolves or acquires an $\mathrm{R}$ protein that recognizes the modified target of HopZ1a, and uses this as a cue to induce the defense response, making the plant host resistant to the pathogen.

(C) Strong positive selection imposed by the host R protein results in the evolution of modified HopZ T3SEs (e.g., HopZ1b and HopZ1c) or the acquisition of homologs from ecologically similar plant pathogens (e.g., HopZ2 and HopZ3). These T3SEs retain cysteine-protease function, but are not recognized by the $\mathrm{R}$ protein, and therefore do not induce a defense response. They may avoid R-protein recognition by either attacking a new virulence target in the host, or by modifying the original target so that it is not recognized by the $\mathrm{R}$ protein. doi:10.1371/journal.pgen.0020209.g007

their cysteine-protease function, but are not all recognized by the $\mathrm{R}$ protein that responds to the ancestral HopZ1a. While none of the derived alleles induce a defense response in their respective hosts, the ancestral allele does, indicating that this arms race has selected for alleles that can avoid or suppress host recognition. It is important to note that these evolutionary dynamics likely occurred over many millions of years, and without information regarding the host targets and resistance genes it is impossible to determine the relative importance of host coevolution versus host switching. An important area of future research will be to determine if these T3SEs modify different virulence targets in their hosts, as suggested by the HopZ3 substrate specificity results, or, alternatively, whether the original virulence target is modified in such a way that it does not induce R-protein signaling. Furthermore, it will be very interesting to identify the resistance protein that recognizes these T3SEs, and to perform parallel evolutionary analyses.

In this study we find a diversity of functional HopZ homologs that are able to evade the detection of $\mathrm{R}$ proteins, as well as degenerate alleles, suggesting that altering the effector rather than losing it may be an important strategy utilized by bacterial pathogens to overcome host recognition. It is particularly noteworthy that these alternative allelic forms have evolved both through pathoadaptive change via the mutational process, as well as through horizontal transfer. Horizontal gene transfer and gene loss are well-known and accepted mechanisms for modifying T3SE-mediated hostspecific interactions [11,27,28,33,46], yet pathoadaptation in this context is less well-understood. While pathoadaptation is well-established in other virulence-associated systems such as the Escherichia coli fimH loci [29,30], it has not yet been shown to influence T3SE-host interactions. The closest examples to pathoadaptive T3SE mutations are the replication-slippage mutations of the 102-bp repeat in the avrBs3 locus from $X$. campestris [34], and the insertion of mobile elements into Ralstonia solanacearum and X. campestris T3SEs [36-38]. Perhaps more telling is the work of Stevens et al. [39], who identified multiple alleles of the P. syringae T3SE, AvrPphE, which are recognized by an $\mathrm{R}$ protein carried by different bean cultivars. Unfortunately, the importance of this natural variation is difficult to ascertain since the T3SEs were expressed from strong constitutive promoters in all of the interaction studies.

There is substantial debate over the relative importance of the population genetics arms-race model verses the trenchwarfare model in describing pathogen-host interactions $[7,27,42,47-51]$. These discussions specifically frame the arms-race model as a continual selective turnover of alleles driven by selective sweeps of favored alleles, and the trenchwarfare model as a dynamic maintenance of genetic variation driven by changes in resistance-allele frequencies [7]. The former scenario emphasizes positive selection, while the latter predicts some form of balancing or diversifying selection. While the strong positive selection seen in hopZ1 appears to support the arms-race model, the extensive genetic variation evident in the HopZ family as a whole could be seen as supporting the trench warfare model. As is often the case, both models likely describe some aspect of these interactions. The particular model that is dominant may depend upon the scale of examination.

This study sheds new light on the role of natural genetic variation in pathogen-host interactions, and provides insight into both the evolutionary and functional mechanisms underlying coevolutionary interactions. It provides a clearer picture of the molecular interactions that drive arms races, and insight into how ecological processes play out at the molecular and evolutionary scale.

\section{Materials and Methods}

Bacterial strains. $P$. syringae isolates (Table S1) were grown in King's $\mathrm{B}$ medium at $30^{\circ} \mathrm{C}$. Minimal medium supplemented with fructose was used to induce the expression of the T3SEs [52].

HopZ characterization. Genes encoding the T3SEs hopZ1a, hopZ1c, $h o p Z 2$, and hopZ3 were obtained by PCR (primers available from 
authors upon request). Genomic DNA from 96 P. syringae strains was prepared using the PureGene DNA isolation protocol (Gentra Systems, http://www.gentra.com). according to the manufacturer's instructions. The DNA was digested and hybridized with the four hopZ genes as probes (Gene Images CDP-Star, Amersham Biosciences, http://www4.amershambiosciences.com). hopZ genes were isolated out of all of positive strains by PCR, inverse PCR, and/or molecular cloning to obtain the full-length sequence and the flanking regions. hopZ3 is in an operon immediately downstream of its chaperone. All the hopZ3 alleles were cloned with their chaperones. Multiple clones and PCR products were sequenced for each allele following manufacturer's protocols on a Beckman Coulter CEQ8000 DNA analyzer (Beckman Coulter, http://www.beckmancoulter.com). The promoters were examined for a $h r p$ promoter box, the conserved sequence that directs the transcription of $P$. syringae T3SEs [53]. The expression of all T3SEs was confirmed under T3SS-inducing conditions by RT-PCR and Northern blot analysis (Figure S1). PCR products and clones were sequenced following manufactures protocols on a Beckman-Coulter CEQ8000 DNA analyzer. GenBank accession numbers for all of the sequenced alleles are presented in Table S2.

Protein purification and protease-activity assay. hopZ genes (hopZ3 was cloned without its chaperone) and their cysteine-to-alanine replacement mutants were amplified by PCR and cloned into the pET14b vector (Novagen, http://www.emdbiosciences.com). The Histagged fusion proteins were overexpressed in E. coli BL21 cells (Novagen), purified using nickel columns, and dialyzed in reaction buffer (100 mM Tris [pH 8.0], $150 \mathrm{mM} \mathrm{NaCl}, 1 \mathrm{mM}$ DTT). Protease activity was measured using both RediPlate 96 EnzChek Protease Assay Kit green fluorescence (Invitrogen, http://invitrogen.com) and a gelatine in-gel assay. Plant extract was obtained from $N$. benthamiana by grinding leaf tissue in the reaction buffer and then spinning at $14,000 \mathrm{rpm}$ for $10 \mathrm{~min}$. $100 \mathrm{ng}$ of plant extract was added to each reaction. The gelatine in-gel assays were performed as previously described [54]. Type A gelatine from porcine skin (Sigma-Aldrich Inc., http://www.sigmaaldrich.com) was added to $10 \%$ acrylamide to a final concentration of $1 \mathrm{mg} / \mathrm{mL}$ to make gelatine-polyacrylamide gels Native protein samples (with and without plant extract) were loaded on the gel, which was run as a regular SDS-PAGE. After running, the gel was incubated at $30{ }^{\circ} \mathrm{C}$ in $2.5 \%$ Triton X-100 for $2 \mathrm{~h}$, and then switched to a protease-activation buffer $(50 \mathrm{mM}$ sodium phosphate buffer [pH6.8], 0.1\% Triton X-100, 5 mM L-cysteine) overnight. Degradation of gelatine was detected by staining the gel in Coomassie Blue.

Agrobacterium-mediated transient-expression assay. hopZ genes were cloned into pMDD1 vector [55], and transformed into Agrobacterium tumefaciens C58C1 (pCH32). hopZ3 was cloned both with and without its upstream chaperone for these assays. The resulting bacteria were pressure-infiltrated into 3 -wk-old $N$. benthamiana leaves [14]. Plants were kept at room temperature under continuous low light for $48 \mathrm{~h}$ before HR was scored.

Hypersensitive response assays. hopZ1 $a_{P S y A 2}$ with its native promoter was cloned into broad-host range vector pUCP20 to construct pUCP20HopZ1a ${ }_{P S y A 2}$. This plasmid was then transformed into $P$. syringae isolates PgyBR1, PmaES4326, PseHC-1, and Por36-1 by electroporation $(2.5 \mathrm{kV}, 25 \mu \mathrm{F}, 600 \Omega)$. The resulting bacteria were hand-infiltrated into leaves of soybean, A. thaliana, sesame, and rice respectively. Soybean (Glycine max cv. OAC Bayfield) was grown in a growth chamber at $22{ }^{\circ} \mathrm{C}$ with a light regime of $16 / 8 \mathrm{~h}$ for $21 \mathrm{~d}$. The unifoliars were infiltrated with a $5 \times 10^{8} \mathrm{cfu} / \mathrm{mL}$ suspension of bacteria, and HR was scored after $48 \mathrm{~h}$. Sesame (Sesamum indicum) was grown in the greenhouse for $6 \mathrm{wk}$ before the primary leaves were infiltrated with a $1 \times 10^{7} \mathrm{cfu} / \mathrm{mL}$ suspension of bacteria. The HR was scored after $24 \mathrm{~h}$. Rice plants (Oryza sativa cv. Jefferson) were grown in a growth chamber at $26-28{ }^{\circ} \mathrm{C}$ at $80 \%$ humidity for $7 \mathrm{~d}$, and the first leaf of each plant was infiltrated with a $5 \times 10^{7} \mathrm{cfu} / \mathrm{mL}$ bacteria suspension. The infiltrated plants were kept at room temperature with continuous light for $24 \mathrm{~h}$, and then transferred back to the growth chamber for an additional 2-48 $\mathrm{h}$ before the HR was scored. The HR assay on A. thaliana eco. Col was performed as previously described [56]. All assays were performed in triplicate along with pUCP20 [57] as controls.

Data analysis. DNA sequence data was manually analyzed and edited with BioEdit version 7.0 (http://www.mbio.ncsu.edu/BioEdit/ bioedit.html). Alignments were made in ClustalX version 1.83 [58] and Dialign2 [59], and manipulated in GeneDoc version 2.6 (www.psc.edu/biomed/genedoc). Phylogenetic analyses were performed in MEGA version 3.1 [60] and Phylip version 3.65 [61]. All trees were constructed using both neighbor-joining and maximumlikelihood methods. Nucleotide trees were constructed with the Kimura two-parameter model using a 2:1 transition-transversion rate and gamma correction for rate heterogeneity $(\alpha=0.2)$. Protein trees were constructed with the JTT substitution matrix. Bootstrapping was performed with 1,000 pseudoreplicates. All neighbor-joining and maximum-likelihood trees were entirely congruent with respect to their major branching; therefore, only neighbor-joining trees are presented. Population-genetic analyses were performed with DnaSP [62] and MEGA. Split decomposition network analysis was performed via SplitsTree version 3.2 [63,64].

PAML version 3.15 [44] analyses were performed using the codeml module. Models M0 (one-ratio), M1 (neutral), M2 (selection), M3 (discrete), M7 (beta), and M8 (beta $+\omega)$ were analyzed. PHYIP was used to generate a maximum-likelihood tree for the treefile. The following parameters settings were used in the control file: CodonFreq $=2$, clock $=0$, aaDist $=0$, model $=0$, cleandata $=0$, fix_kappa $=0$, fix_omega $=0$. Likelihood ratio tests were performed to determine the relative significance of the models using the degrees of freedom specified in Table S2.

\section{Supporting Information}

Figure S1. Expression Analysis of HopZ T3SEs

(A) RT-PCR analysis. (B) Northern analysis. u, uninduced; i, induced for T3SS expression.

Found at doi:10.1371/journal.pgen.0020209.sg001 (3.6 MB TIF).

Figure S2. Gene Genealogy of the HopZ Family

Midpoint-rooted neighbor-joining phylogenetic analysis of all HopZ T3SEs in $P$. syringae, based on the DNA sequence. Numbers above nodes represent 1,000 bootstrap replicates. Only those values with $>60 \%$ support are shown.

Found at doi:10.1371/journal.pgen.0020209.sg002 (2.1 MB TIF).

Figure S3. Protein Multiple Sequence Alignment of All HopZ1 Alleles Shading indicates the degree of conservation. The arrows indicate the three amino acids ( $\mathrm{H}$, histidine; $\mathrm{E}$, glutamic acid; $\mathrm{C}$, cysteine) that form the catalytic triad.

Found at doi:10.1371/journal.pgen.0020209.sg003 (3.6 MB TIF).

Figure S4. Split Decomposition Network Phylogenetic Analysis of the hopZ1 Homologs

Numbers along the branches are bootstrap scores from 1,000 pseudoreplicates. Only those bootstrap scores above 50 are shown. Found at doi:10.1371/journal.pgen.0020209.sg004 (1.3 MB TIF).

Table S1. Pseudomonas syringae Strains Found at doi:10.1371/journal.pgen.0020209.st001 (237 KB DOC).

Table S2. GenBank Accession Numbers Found at doi:10.1371/journal.pgen.0020209.st002 (58 KB DOC).

\section{Acknowledgments}

We would like to acknowledge Drs. Malcolm Campbell and Darrell Desveaux for their thoughtful critique of the manuscript, and Dr. Pauline Wang, Robyn Morgan, and Alex Hui for their input to the project. Drs. Darrell Desveaux and Dinesh Christendat and William Urquhart provided invaluable technical support. We would like to thank Dr. Mary Beth Mudgett for providing pMDD1 and A. tumefaciens C58C1(pCH32), and the members of the $P$. syringae research community for providing strains.

Author contributions. WM and DSG conceived and designed the experiments. WM and FFTD performed the experiments. JS and DSG analyzed the data. DSG contributed reagents/materials/analysis tools. WM, JS, and DSG wrote the paper.

Funding. WM was supported by a postdoctoral fellowship from the Natural Sciences and Engineering Research Council (NSERC) of Canada. JS is a NSERC Canada Graduate Scholar. DSG is supported by grants from the Canada Research Chairs program, NSERC, and Performance Plants, Kingston, Ontario, Canada.

Competing interests. The authors have declared that no competing interests exist. 


\section{References}

1. Dawkins R, Krebs JR (1979) Arms races between and within species. Proc R Soc Lond B Biol Sci 205: 489-511.

2. Bergelson J, Dwyer G, Emerson JJ (2001) Models and data on plant-enemy coevolution. Annu Rev Genet 35: 469-499.

3. Clay K, Kover PX (1996) The Red Queen hypothesis and plant/pathogen interactions. Annu Rev Phytopathol 34: 29-50.

4. Mota LJ, Cornelis GR (2005) The bacterial injection kit: Type III secretion systems. Ann Med 37: 234-249.

5. Jackson RW, Athanassopoulos E, Tsiamis G, Mansfield JW, Sesma A, et al (1999) Identification of a pathogenicity island, which contains genes for virulence and avirulence, on a large native plasmid in the bean pathogen Pseudomonas syringae pathovar phaseolicola. Proc Natl Acad Sci U S A 96 10875-10880.

6. Jamir Y, Guo M, Oh HS, Petnicki-Ocwieja T, Chen S, et al. (2004) Identification of Pseudomonas syringae type III effectors that can suppress programmed cell death in plants and yeast. Plant J 37: 554-565.

7. Stahl EA, Dwyer G, Mauricio R, Kreitman M, Bergelson J (1999) Dynamics of disease resistance polymorphism at the Rpm1 locus of Arabidopsis. Nature 400: $667-671$.

8. Rohmer L, Guttman DS, Dangl JL (2004) Diverse evolutionary mechanisms shape the type III effector virulence factor repertoire in the plant pathogen Pseudomonas syringae. Genetics 167: 1341-1360.

9. Alfano JR, Collmer A (2004) Type III secretion system effector proteins Double agents in bacterial disease and plant defense. Annu Rev Phytopathol 42: 385-414.

10. Wichmann G, Ritchie D, Kousik CS, Bergelson J (2005) Reduced genetic variation occurs among genes of the highly clonal plant pathogen Xanthomonas axonopodis pv. vesicatoria, including the effector gene avrBs2. Appl Environ Microbiol 71: 2418-2432.

11. Pitman AR, Jackson RW, Mansfield JW, Kaitell V, Thwaites R, et al. (2005) Exposure to host resistance mechanisms drives evolution of bacterial virulence in plants. Curr Biol 15: 2230-2235.

12. Hotson A, Mudgett MB (2004) Cysteine proteases in phytopathogenic bacteria: Identification of plant targets and activation of innate immunity. Curr Opin Plant Biol 7: 384-390.

13. Orth K, Xu Z, Mudgett MB, Bao ZQ, Palmer LE, et al. (2000) Disruption of signaling by Yersinia effector YopJ, a ubiquitin-like protein protease. Science 290: 1594-1597.

14. Roden J, Eardley L, Hotson A, Cao Y, Mudgett MB (2004) Characterization of the Xanthomonas AvrXv4 effector, a SUMO protease translocated into plant cells. Mol Plant Microbe Interact 17: 633-643.

15. Mukherjee S, Keitany G, Li Y, Wang Y, Ball HL, et al. (2006) Yersinia YopJ acetylates and inhibits kinase activation by blocking phosphorylation. Science 312: 1211-1214.

16. Lindeberg M, Stavrinides J, Chang JH, Alfano JR, Collmer A, et al. (2005) Proposed guidelines for a unified nomenclature and phylogenetic analysis of type III Hop effector proteins in the plant pathogen Pseudomonas syringae. Mol Plant Microbe Interact 18: 275-282.

17. Sundin GW, Mayfield CT, Zhao Y, Gunasekera TS, Foster GL, et al. (2004) Complete nucleotide sequence and analysis of pPSR1 (72,601 bp), a pPT23A-family plasmid from Pseudomonas syringae pv. syringae A2. Mol Genet Genomics 270: 462-476.

18. Guttman DS, Vinatzer BA, Sarkar SF, Ranall MV, Kettler G, et al. (2002) A functional screen for the type III (Hrp) secretome of the plant pathogen Pseudomonas syringae. Science 295: 1722-1726.

19. Arnold DL, Jackson RW, Fillingham AJ, Goss SC, Taylor JD, et al. (2001) Highly conserved sequences flank avirulence genes: Isolation of novel avirulence genes from Pseudomonas syringae pv. pisi. Microbiology 147: 11711182.

20. Deng WL, Rehm AH, Charkowski AO, Rojas CM, Collmer A (2003) Pseudomonas syringae exchangeable effector loci: Sequence diversity in representative pathovars and virulence function in $P$. syringae pv. syringae B728a. J Bacteriol 185: 2592-2602.

21. Charity JC, Pak K, Delwiche CF, Hutcheson SW (2003) Novel exchangeable effector loci associated with the Pseudomonas syringae hrp pathogenicity island: Evidence for integron-like assembly from transposed gene cassettes. Mol Plant Microbe Interact 16: 495-507

22. Vinatzer BA, Teitzel GM, Lee MW, Jelenska J, Hotton S, et al. (2006) The type III effector repertoire of Pseudomonas syringae pv. syringae B728a and its role in survival and disease on host and non-host plants. Mol Microbiol 62: $26-44$.

23. Mudgett MB (2005) New insights to the function of phytopathogenic bacterial type III effectors in plants. Annu Rev of Plant Biol 56: 509-531.

24. Chang JH, Goel AK, Grant SR, Dangl JL (2004) Wake of the flood: Ascribing functions to the wave of type III effector proteins of phytopathogenic bacteria. Curr Opin Microbiol 7: 11-18.

25. Bretz JR, Hutcheson SW (2004) Role of type III effector secretion during bacterial pathogenesis in another kingdom. Infect Immun 72: 3697-3705.

26. Alfano JR, Collmer A (2004) Type III secretion system effector proteins: Double agents in bacterial disease and plant defense. Annu Rev Phytopathol 42: 385-414.

27. Araki H, Tian D, Goss EM, Jakob K, Halldorsdottir SS, et al. (2006) Presence absence polymorphism for alternative pathogenicity islands in Pseudomonas viridiflava, a pathogen of Arabidopsis. Proc Natl Acad Sci U S A 103: 58875892

28. Sarkar SF, Gordon JS, Martin GB, Guttman DS (2006) Comparative genomics of host-specific virulence in Pseudomonas syringae. Genetics 174: 1041-1056.

29. Sokurenko EV, Hasty DL, Dykhuizen DE (1999) Pathoadaptive mutations: Gene loss and variation in bacterial pathogens. Trends Microbiol 7: 191195.

30. Sokurenko EV, Chesnokova V, Dykhuizen DE, Ofek I, Wu XR, et al. (1998) Pathogenic adaptation of Escherichia coli by natural variation of the FimH adhesin. Proc Natl Acad Sci U S A 95: 8922-8926.

31. Sokurenko EV, Feldgarden M, Trintchina E, Weissman SJ, Avagyan S, et al. (2004) Selection footprint in the FimH adhesin shows pathoadaptive niche differentiation in Escherichia coli. Mol Biol Evol 21: 1373-1383.

32. Weissman SJ, Moseley SL, Dykhuizen DE, Sokurenko EV (2003) Enterobacterial adhesins and the case for studying SNPs in bacteria. Trends Microbiol 11: 115-117.

33. Rohmer L, Guttman DS, Dangl JL (2004) Diverse evolutionary mechanisms shape the type III effector virulence factor repertoire in plant pathogenic Pseudomonas syringae. Genetics 167: 1341-1360.

34. Herbers K, Conrads-Strauch J, Bonas U (1992) Race-specificity of plant resistance to bacterial spot disease determined by repetitive motifs in a bacterial avirulence protein. Nature 356: 172-174.

35. Yang Y, Gabriel DW (1995) Intragenic recombination of a single plant pathogen gene provides a mechanism for the evolution of new host specificities. J Bacteriol 177: 4963-4968.

36. Lavie M, Seunes B, Prior P, Boucher C (2004) Distribution and sequence analysis of a family of type III-dependent effectors correlate with the phylogeny of Ralstonia solanacearum strains. Mol Plant Microbe Interact 17: 931-940.

37. Robertson AE, Wechter WP, Denny TP, Fortnum BA, Kluepfel DA (2004) Relationship between avirulence gene (avrA) diversity in Ralstonia solanacearum and bacterial Wilt incidence. Mol Plant Microbe Interact 17: $1376-1384$.

38. Kearney B, Ronald PC, Dahlbeck D, Staskawicz BJ (1988) Molecular basis for evasion of plant host defense in bacterial spot disease of pepper. Nature 332: $541-543$

39. Stevens C, Bennett MA, Athanassopoulos E, Tsiamis G, Taylor JD, et al. (1998) Sequence variations in alleles of the avirulence gene avrPphE.R2 from Pseudomonas syringae pv. phaseolicola lead to loss of recognition of the AvrPphE protein within bean cells and a gain in cultivar-specific virulence. Mol Microbiol 29: 165-177.

40. Sarkar SF, Guttman DS (2004) The evolution of the core genome of Pseudomonas syringae, a highly clonal, endemic plant pathogen. Appl Environ Microbiol 70: 1999-2012.

41. Cuff JA, Clamp ME, Siddiqui AS, Finlay M, Barton GJ (1998) JPred: A consensus secondary structure prediction server. Bioinformatics 14: 892893.

42. Guttman DS, Gropp SJ, Morgan RL, Wang PW (2006) Diversifying selection drives the evolution of the type III secretion system pilus of Pseudomonas syringae. Mol Biol Evol. e-pub 1 September 2006.

43. Shimodaira H, Hasegawa M (1999) Multiple comparisons of log-likelihoods with applications to phylogenetic inference. Mol Biol Evol 16: 1114-1116.

44. Yang ZH (1997) PAML: A program package for phylogenetic analysis by maximum likelihood. Comput Appl Biosci 13: 555-556.

45. Dangl JL, Jones JD (2001) Plant pathogens and integrated defence responses to infection. Nature 411: 826-833.

46. Prager R, Mirold S, Tietze E, Strutz U, Knuppel B, et al. (2000) Prevalence and polymorphism of genes encoding translocated effector proteins among clinical isolates of Salmonella enterica. Int J Med Microbiol 290: 605-617.

47. Mauricio R, Stahl EA, Korves T, Tian D, Kreitman M, et al. (2003) Natural selection for polymorphism in the disease resistance gene RPS2 of Arabidopsis thaliana. Genetics 163: 735-746.

48. Moeller DA, Tiffin P (2005) Genetic diversity and the evolutionary history of plant immunity genes in two species of Zea. Mol Biol Evol 22: 2480-2490.

49. Tiffin P, Hacker R, Gaut BS (2004) Population genetic evidence for rapid changes in intraspecific diversity and allelic cycling of a specialist defense gene in Zea. Genetics 168: 425-434

50. Bakker EG, Toomajian C, Kreitman M, Bergelson J (2006) A genome-wide survey of R gene polymorphisms in Arabidopsis. Plant Cell 18: 1803-1818.

51. Allen RL, Bittner-Eddy PD, Grenvitte-Briggs LJ, Meitz JC, Rehmany AP, et al. (2004) Host-parasite coevolutionary conflict between Arabidopsis and downy mildew. Science 306: 1957-1960.

52. Zwiesler-Vollick J, Plovanich-Jones AE, Nomura K, Bandyopadhyay S, Joardar V, et al. (2002) Identification of novel hrp-regulated genes through functional genomic analysis of the Pseudomonas syringae pv. tomato DC3000 genome. Mol Microbiol 45: 1207-1218.

53. Innes RW, Bent AF, Kunkel BN, Bisgrove SR, Staskawicz BJ (1993) Molecular analysis of avirulence gene avrRpt2 and identification of a putative regulatory sequence common to all known Pseudomonas syringae avirulence genes. J Bacteriol 175: 4859-4869.

54. Michaud D, Faye L, Yelle S (1993) Electrophoretic analysis of plant cysteine and serine proteinases using gelatin-containing polyacrylamide gels and class-specific proteinase-inhibitors. Electrophoresis 14: 94-98.

55. Mudgett MB, Chesnokova O, Dahlbeck D, Clark ET, Rossier O, et al. (2000) 
Molecular signals required for type III secretion and translocation of the Xanthomonas campestris AvrBs2 protein to pepper plants. Proc Natl Acad Sci U S A 97: 13324-13329.

56. Guttman DS, Greenberg JT (2001) Functional analysis of the type III effectors AvrRpt2 and AvrRpm1 of Pseudomonas syringae with the use of a single-copy genomic integration system. Mol Plant Microbe Interact 14: $145-155$.

57. West SEH, Schweizer HP, Dall C, Sample AK, Runyenjanecky LJ (1994) Construction of improved Escherichia-Pseudomonas shuttle vectors derived from pUC18/19 and sequence of the region required for their replication in Pseudomonas aeruginosa. Gene 148: 81-86.

58. Chenna R, Sugawara H, Koike T, Lopez R, Gibson TJ, et al. (2003) Multiple sequence alignment with the Clustal series of programs. Nucleic Acids Res 31: $3497-3500$.

59. Morgenstern B (1999) DIALIGN 2: Improvement of the segment-tosegment approach to multiple sequence alignment. Bioinformatics 15 : 211-218.

60. Kumar S, Tamura K, Nei M (2004) MEGA3: Integrated software for molecular evolutionary genetics analysis and sequence alignment. Brief Bioinform 5: 150-163.

61. Felsenstein J (1993) PHYLIP (phylogeny inference package). 3.5c edition. Seattle: Department of Genetics, University of Washington, distributed by the author. Available at http://evolution.genetics.washington.edu/phylip. html. Accessed 30 October 2006.

62. Rozas J, Sanchez-DelBarrio JC, Messeguer X, Rozas R (2003) DnaSP, DNA polymorphism analyses by the coalescent and other methods. Bioinformatics 19: 2496-2497.

63. Huson DH (1998) SplitsTree: Analyzing and visualizing evolutionary data. Bioinformatics 14: 68-73.

64. Bandelt HJ, Dress AW (1992) Split decomposition: A new and useful approach to phylogenetic analysis of distance data. Mol Phylogenet Evol 1: 242-252.

65. Hwang MSH, Morgan RL, Sarkar SF, Wang PW, Guttman DS (2005) Phylogenetic characterization of virulence and resistance phenotypes in Pseudomonas syringae. Appl Environ Microbiol 71: 5182-5191. 